\title{
INVENTÁRIO DE SEXISMO AMBIVALENTE: SUA ADAPTAÇÃO E RELAÇÃO COM O GÊNERO ${ }^{1}$
}

\author{
Nilton S. Formiga* \\ Valdiney V. Golveia" \\ Maria Neusa dos Santos
}

\begin{abstract}
RESUMO. O objetivo deste estudo foi adaptar para o Brasil o Inventário de Sexismo Ambivalente (Glick \& Fiske, 1996), assim como conhecer em que medida suas pontuações são diferentes em função do gênero. Este instrumento é constituído por 22 itens, respondidos em escala de cinco pontos, tipo Likert e teoricamente avalia dois fatores: sexismo hostil e sexismo benévolo. A amostra foi composta de 200 graduandos do curso de Psicologia de uma universidade privada, de ambos os sexos. A aplicação deste inventário foi coletiva, nas salas de aula, garantido o anonimato das respostas. Os resultados confirmaram a existência dos dois fatores hipotetizados, e indicaram uma correlação do sexismo com o gênero; especificamente, os homens apresentam maior sexismo hostil, enquanto as mulheres pontuaram mais em relação ao sexismo benévolo. Estes resultados são discutidos à luz da literatura sobre os estereótipos de gênero.
\end{abstract}

Palavras-chaves: produção de subjetividade, sociedade de controle, risco.

\section{AMBIVALENT SEXISM INVENTORY: ITS ADAPTATION AND CORRELATION WITH GENDER}

\begin{abstract}
This study aimed (1) to adapt the Ambivalent Sexism Inventory (Glick \& Fiske, 1996) to the Brazilian reality, and (2) to evaluate the variability of its scores in relation to gender. This instrument is composed of 22 items that should be responded to on 5-point Likert-scale; theoretically, it evaluates two factors: hostile sexism and benevolent sexism. Two hundred (male and female) Psychology undergraduate students of a private university took part in the sample. The questionnaires were completed collectively during class, and the subjects were assured of the anonymity of their answers. The results confirmed the existence of both hypothesized factors, and indicated a correlation of sexism with gender. Specifically, male score were higher in hostile sexism, while female scores were higher in benevolent sexism. These results are discussed with the stereotype of gender background found in the literature.
\end{abstract}

Key words: sexism, stereotype, gender.

\section{INTRODUÇÃO}

$\mathrm{Na}$ Constituição Brasileira de 1988 especificamente no que se refere ao7s direitos e deveres individuais e coletivos, figura no artigo $5^{\circ} \mathrm{do}$ parágrafo $1^{\circ}$ que homens e mulheres são iguais em direitos e obrigações. Moraes (1998) especifica claramente esta parte da constituição e comenta que a desigualdade entre os gêneros é proibida, sendo enfatizada na lei uma plena igualdade. Não obstante, esta pretendida igualdade é apenas parcialmente comprovada na realidade cotidiana; por exemplo, exercendo a mesma função e tendo o mesmo grau de escolaridade, a mulher segue recebendo menores salário que os homem (Fundação Carlos Chagas, 1998). As razões para tanto, muito provavelmente, se

\footnotetext{
O presente estudo foi desenvolvido no Laboratório de Avaliação e Medida Psico-Social (LAMPS), Universidade Federal da Paraíba, CCHLA, Departamento de Psicologia.

* Mestre em Psicologia Social, docente do CEULP, Universidade Luterana do Brasil - ULBRA.

Endereço para correspondência: Coordenação de Psicologia, Curso de Psicologia, Av. Teotônio Segurado, 1501, Sul, 77054-970, Cx. P. 160, Palmas, TO. E-mail: nsformiga@yahoo.com ou nsformiga@ulbra-to.br

\# Doutor em Psicologia Social, docente da Universidade Federal da Paraíba. Durante a realização deste estudo contei com Bolsa Produtividade do CNPq.

II Docente do Centro Universitário de João Pessoa, UNIPÊ.
} 
radicam principalmente na visão estereotipada do papel e da capacidade de ambos os gêneros.

O tema da discriminação da mulher permite muitas especulações em âmbitos diversos das ciências humanas e sociais. Causas e conseqüências podem ser hipotetizadas e defendidas, porém não se conhecerá sua verdadeira extensão se não se consideram diretamente os agentes que a fomentam: homens e mulheres da sociedade civil. Suas opiniões, atitudes e pensamentos sobre o papel da mulher em diferentes facetas da sociedade são cruciais no momento de compreender formas e conteúdos do sexismo. Dispor de uma medida válida e precisa pode ser um primeiro passo para aprofundar esta temática, e é isto precisamente o que anima o presente estudo. Os instrumentos, no Brasil, que permitem medir o sexismo são escassos; o Inventário de Seximo Ambivalente (Glick \& Fiske, 1996) vem sendo recentemente utilizado, mas não são analisados seus parâmetros psicométricos (D'Amorim, 1997). Neste sentido, o objetivo principal da presente pesquisa é comprovar sua adequação à realidade brasileira, procurando demonstrar sua validade de construto; pretende-se igualmente conhecer em que medida suas pontuações diferem em função do gênero do respondente.

\section{O CONTEXTO DO SEXISMO}

Ultimamente, movimentos que defendem a igualdade dos direitos civis e políticos da mulher têm se manifestado com grande força. Estes compreendem uma tentativa organizada de lutar pela equiparação incondicional dos gêneros quanto aos direitos humanos, refletindo um esforço por integrar as estruturas monolíticas do capitalismo e do patriarcado a uma nova visão desenvolvimentista e histórica, que discute a dominação do gênero e sua inter-relação com as classes, a etnicidade, a sexualidade, a política e a cultura (ver Fukuyama, 2000; Pringle, 1997). Segundo Fraisse (1991; Outram, 1997), já no século XIX as mudanças ocorridas na economia, na sociedade como um todo e na política favoreceram o surgimento de discursos que levaram ao reconhecimento da desigualdade sofrida pelas mulheres e da superioridade imposta pelos homens. Isto parecia ser o prelúdio de uma igualdade universal como princípio orientador, discutida nos escritos de A Democracia na América (De Tocqueville, 1835 / 1993), mas que não se concretizou ao ter que se render ao sentido unilateral da liberdade e autonomia do homem, do macho. Esta situação refletiu especialmente o contexto e padrão cultural latino ou hispânico, cuja orientação social, inclusive nas décadas recentes, reflete discursos e pensamentos que evidenciam a masculinidade (Hofstede, 1991) e o machismo (Goldwert, 1985; Pena, 1991; Torres, 1998).

O desenvolvimento econômico e a luta pela sobrevivência levaram tanto a sociedade civil como os cientistas sociais a refletir sobre a construção do gênero como prática "imposta" socialmente. No caso das mulheres, estas deveriam cuidar da família, dos filhos e da casa; suas relações e papéis no matrimônio e sua sexualidade evidenciavam um ser passivo, servidor. Ao homem cabia o trabalho fora do lar, o que deveria assegurar o sustento da sua família. Dono e senhor, este era livre, inclusive para dispor do seu corpo e se entregar a diversões noturnas e prazeres extramatrimoniais (Borreli, 1998). Em face dessa situação, a mulher passou a espelhar a imagem de um ser frágil, sentimental e sensível, estando associada a uma orientação expressiva com ênfase na interdependência e feminilidade; os homens, por sua vez, tomavam as decisões, fundamentavam sua ação em juízos racionais, dispondo de uma visão instrumental do mundo (Hutz \& Koller, 1992; Katsurada \& Sugihara, 1999; Lenney, 1991) e dos fatos $^{2}$. Isto sem dúvida fazia crer na debilidade e inferioridade das mulheres quando comparadas com os homens.

Com o passar dos anos a distinção entre gêneros se baseou nas concepções de masculinidade e feminilidade, entendidas em termos estritos. Estas sublinhavam que a identidade de homem e mulher se dava através da aceitação consciente do sexo biológico. Esta é evidente já a partir do nascimento, sendo corroborada no transcurso do desenvolvimento, quando a criança consegue (ou é levada a) destinguir os atributos, atitudes e comportamentos que são vinculados a cada sexo biológico. Através de tais associações a criança começa a construir um esquema conceitual de gênero que por sua vez é responsável pelo processamento de novas informações e avaliações de preferências e atitudes, conformando a idéia e contribuindo para a escolha do papel sexual. Neste sentido, pode-se dizer que é através do autoconceito ou autopercepção que cada indivíduo incorpora os atributos instrumentais ou expressivos aceitos culturalmente (ver Souza \& Ferreira, 1997; Spence, Helmreich \& Stapp, 1975; Steinmann, 1977). Desta maneira, reconhece-se que a sociedade está impregnada de ideologias que guiam e justificam as condutas do indivíduo, fazendo com que estas sejam

2 para conhecer a diferença percebida entre os gêneros na cultura brasileira, ver Ferreira, 1995a, 1995b. 
"comuns" e sirvam como base para que homens e mulheres adotem esquemas psicológicos e ideológicos que refletem comportamentos a respeito da formação discriminatória de papéis sexuais (Paéz, Torres \& Echebarría, 1990). Para Archer (1996) estas discriminações ainda prevalecem e estão fortalecidas devido àpredominância que o macho teve no passado, sustentada por concepções enviesadas que atribuíam aos homens uma diferença e maior capacidade quando comparados com as mulheres. Porém, esta forma flagrante do sexismo parece estar condenada a sucumbir. Na sociedade atual, com sanções legais contra juízos e condutas discriminatórias em relação ao gênero, o sexismo parece estar tomando novos contornos. A exemplo do preconceito contra grupos minoritários (negros, homossexuais, etc.), que passou a ser mais sutil e disfarçado (Pettigrew \& Meertens, 1995; ver também Swim, Aikin, Hall \& Hunter, 1995), surgem novas formas de expressar avaliações negativas em relação às mulheres.

\section{O NOVO SEXISMO}

Como observado acima, as concepções a respeito da diferença entre os sexos referem-se a diferentes aspectos: históricos, biológicos, econômicos, sociológicos, etc. (ver também Unger, 1979). O gênero evidencia uma relação de poder distribuída assimetricamente na sociedade, sendo que tal diferenciação ou presumível hierarquia, seja através das questões sociais seja das psicológicas, não pode ser considerada isoladamente do contexto em que é fomentada (Ferreira, 1995b; Souza \& Ferreira, 1997). A propósito, existe um amplo conjunto de teorias e práticas que, ligadas ao contexto cultural, facilitam a compreensão das semelhanças e diferenças entre os gêneros (Borelli, 1998; Eagleton, 1998). Não é objetivo aqui tratar todos os modelos teóricos existentes. Dentro de uma linha sociocognitiva, pretende-se uma aproximação às pesquisas que compreendem o sexismo como um conjunto de estereótipos sobre a avaliação cognitiva, afetiva e atitudinal acerca do papel apropriado na sociedade, dirigida aos indivíduos de acordo com o sexo (Expósito, Moya \& Glick, 1996; Glick \& Fiske, 1996).

Partindo desta concepção, Glick e Fiske (1996) destacam a vigência de novas formas de sexismo, entendidas como ambivalentes por não serem tão diretas e claras como as posturas mais tradicionais de discriminação, geralmente baseadas na assumida inferioridade ou diferença das mulheres como um grupo. Como assinalam Mladinic, Saiz, Díaz,Ortega e
Oyarce (1998), não se trata simplesmente da definição tradicional de preconceito como antipatia ou hostilidade a membros de certos grupos sociais, discutido na obra de Allport (1994), impedindo com isso, apreender a verdadeira essência do sexismo. Diferentemente de outras formas de intolerância social (por exemplo, racial, religiosa, econômica), o preconceito em relação à mulher não é uniformemente negativo. Deste aspecto exatamente deriva a noção de uma manifestação preconceituosa ambivalente.

O sexismo ambivalente apresenta duas formas principais, hostil e benévola, as quais estariam interligadas por três subcomponentes, a saber (Glick \& Fiske, 1996; Mladinic \& cols., 1998):

- Paternalismo: Refere-se ao relacionamento que se estabelece com a mulher no mesmo sentido em que um pai se relaciona com o seu filho, podendo ter um matiz tanto de domínio (paternalismo dominante) como de afeto e proteção (paternalismo protetor). $\mathrm{O}$ primeiro tipo corresponde ao sexismo hostil, caracterizando a mulher como uma pessoa geralmente incapaz, que por isso necessita de uma figura masculina superior; o segundo cobre a expressão do sexismo benévolo, assumindo que a mulher é um ser débil que necessita ser protegido e mantido pelo homem.

- Diferenciação de gênero: no sexismo hostil esta diferenciação se apresenta como competitiva, percebendo-se o homem como exclusivo possuidor de traços e habilidades que são necessários para dirigir as instituições sociais mais importantes. No caso do sexismo benévolo, tem lugar uma diferenciação complementar, onde são identificados atributos positivos na mulher, mas que são complementares aos que possuem os homens.

- Heterossexualidade: destaca-se por um lado que a mulher usa seu atrativo e poder sexual para dominar o homem, e a motivação sexual deste está associada a um desejo de intimidade com a mulher (sexismo hostil); por outro lado, reconhece-se que tanto o homem como a mulher não podem ser completamente felizes em suas vidas se carecem um do outro. A crença, nesta caso, válida principalmente para a mulher, é que sem um companheiro a pessoa deve ser digna de compaixão e ajuda (sexismo benévolo).

O sexismo hostil é uma expressão mais flagrante de preconceito em relação às mulheres, aproximandose da definição clássica deste atributo psicossocial (Allport, 1994). Este tem sido extensamente tratado (Glick \& Fiske, 1996), porém não permite 
compreender totalmente a direção que toma o sexismo na sociedade atual. No contexto de presumível igualdade em direitos e deveres entre os gêneros (Siano, 2000), o sexismo benévolo se constitui na forma mais apropriada de justificar concessões e tratamentos diferenciados entre homens e mulheres. Apresenta-se a seguir um resumo das principais idéias que caracterizam estes dois tipos de sexismo.

Sexismo hostil: evidencia crenças e práticas típicas de pessoas que consideram as mulheres inferiores aos homens, refletindo antipatia e intolerância em relação ao seu papel como figura de poder e decisão. Prima por uma orientação vertical, com obediência aos padrões morais tradicionais que situam a mulher no lar e é mais claro e diretamente discriminatório do que o tipo discutido a seguir. Alguns itens que poderiam caracterizá-lo são: as mulheres tentam ganhar poder controlando os homens; as mulheres exageram os problemas que têm no trabalho; e uma vez que uma mulher consiga que o homem se comprometa com ela, tenta controlá-lo estritamente.

Sexismo benévolo: refere-se a uma atitude positiva, aparentemente não preconceituosa em relação à mulher, evidenciando o sentido paternalista que a descreve como pessoa frágil, que necessita atenção mas que também pode complementar o homem. É, provavelmente, outra faceta dos papéis sexuais instrumental e expressivo, ainda prevalecentes para descrever, respectivamente, homens e mulheres na sociedade contemporânea (ver Mladinic \& cols., 1998). Os seguintes itens poderiam ajudar a defini-lo: as mulheres devem ser queridas e protegidas pelos homens; todo homem deve ter uma mulher a quem amar; e o homem está incompleto sem a mulher.

Como é possível perceber, mesmo na valorização (aparente) da mulher, correspondendo neste caso ao sexismo benévolo, é subentendido o seu papel de mãe, responsável por prover o afeto na família, cuidar dos filhos, do esposo, etc. Sua identidade sexual feminina, nesta perspectiva, define-se em termos de sua dependência, fragilidade e sensibilidade. Deve a mulher complementar o homem e apoiá-los nas suas realizações. Não precisam se expor, romper com sua "natureza feminina" e se aventurar em um mundo de competições. Como comentam Mladinic e cols. (1998), este tipo de sexismo reflete atitudes em relação às mulheres as quais, embora as contemplem de maneira estereotipada e desempenhando papéis restritivos, possuem para o sexista um tom subjetivamente positivo e tendem a estimular comportamentos tipicamente pró-sociais (por exemplo, ajudar as mulheres) ou que promovam a intimidade (por exemplo, revelar às mulheres aspectos pessoais).
Em resumo, embora proibido por lei, o sexismo segue existindo, em maior ou menor medida, em todas as partes do mundo. Deixa de ser uma forma aberta de discriminação contra a mulher, assumindo contornos sutis. Embora ninguém duvide desta possibilidade, para conhecer sua extensão na sociedade civil e lograr uma estimação sobre seu verdadeiro impacto, é necessário também quantificá-lo. Como foi dito anteriormente, o objetivo principal deste estudo representa um primeiro esforço no sentido de contar com uma medida deste construto que possa ser válida e precisa no contexto brasileiro. Esta precisa contemplar os dois componentes de sexismo antes anunciados (hostil e benévolo).

Embora existam evidências a favor de um modelo que contempla o sexismo hostil como uma única dimensão, enquanto o benévolo cobriria diferentemente os três aspectos tratados previamente (paternalismo protetor, diferenciação complementar entre os gêneros e intimidade heterossexual) (Glick \& Fiske, 1996), o presente estudo comprovará a estrutura bifatorial mais conhecida, que contempla diretamente os dois tipos de sexismo: o hostil e o benévolo. Como esses autores têm demonstrado, tal modelo corresponde aos índices de bondade de ajuste esperados; em amostra de estudantes universitários chilenos, este também tem se revelado promissor (Mladinic \& cols., 1998). Finalmente, a natureza do sexismo ambivalente é ainda algo confusa; estima-se a existência de dimensões opostas ao passo que é reconhecido que estas podem estar positivamente relacionadas entre si (Mladinic e cols., 1998). Este aspecto precisará também ser contemplado.

\section{MÉTODO}

\section{Amostra}

Participaram da pesquisa 200 estudantes universitários de ambos os gêneros, do curso de Psicologia do Centro Universitário de João Pessoa (UNIPÊ), a maioria dos quais eram mulheres (85\%), com idade variando de 20 a 56 anos $(\underline{\mathrm{M}}=25,10 ; \underline{\mathrm{DP}}=$ 7,80). Esta amostra é não probabilística, podendo ser definida como intencional; foram consideradas as pessoas que, consultadas, dispuseram-se a colaborar respondendo ao questionário que era apresentado.

\section{Instrumento}

Os participantes responderam a um questionário constando de duas partes: 
- Inventário de Sexismo Ambivalente, ISA: elaborado originalmente em língua inglesa (Glick \& Fiske, 1996), este instrumento é composto por 22 itens que avaliam os estereótipos assumidos por cada gênero (masculino e feminino) a respeito de duas dimensões do sexismo: hostil (por exemplo, As mulheres feministas estão fazendo exigências completamente sem sentido aos homens; a maioria das mulheres não aprecia completamente tudo o que os homens fazem por elas) e benévolo (por exemplo, as mulheres devem ser queridas e protegidas pelos homens; muitas mulheres se caracterizam por uma pureza que poucos homens possuem). Para responder ao questionário, a pessoa deve ler cada item e indicar quanto está de acordo com o conteúdo expresso, utilizando para tanto uma escala de quatro pontos, tipo Likert, com os seguintes extremos: $1=$ Discordo totalmente e $4=$ Concordo totalmente. Esta versão foi traduzida para o português por um psicólogo bilíngüe, e avaliada por um segundo psicólogo bilíngüe, que também a comparou com uma versão espanhola (Expósito, Moya \& Glick, 1998). Feita a tradução, procedeu-se à validação semântica do ISA; para tanto foi considerada uma amostra de 20 sujeitos da população-meta. Esta assegurou que tanto os itens como as instruções que os antecediam eram compreensíveis.

- Caracterização sociodemográfica: uma folha separada foi anexada ao instrumento prévio, onde eram solicitadas informações de caráter sociodemográfico (por exemplo, idade, sexo, estado civil, etc.).

\section{Procedimento}

Procurou-se definir um procedimento-padrão, que consistia em aplicar o ISA coletivamente em sala de aula. Um único pesquisador ficou responsável pela coleta dos dados. Após conseguir a autorização do professor responsável pela disciplina, o pesquisador se apresentava em sala de aula como interessado em conhecer as opiniões e os comportamentos das pessoas no dia-a-dia, solicitando a colaboração voluntária dos estudantes no sentido de responderem a um questionário breve. Foi-lhes dito que não havia respostas certas ou erradas, e que respondessem individualmente; a todos era assegurado o anonimato das suas respostas, que seriam tratadas em seu conjunto. Apesar de o questionário ser auto-aplicável, contando com as instruções necessárias para poderem ser respondidos, o pesquisador esteve presente durante toda a aplicação, para retirar eventuais dúvidas ou realizar esclarecimentos que se fizessem indispensáveis. Um tempo médio de 15 minutos foi suficiente para concluir essa atividade.

\section{Tabulação e análise dos dados}

O pacote estatístico SPSSWIN, em sua versão 8.0, foi utilizado para tabular os dados e realizar as análises estatísticas descritivas, bem como os cálculos referentes ao teste $\underline{t}$ de Student, coeficiente de correlação $\underline{r}$ de Pearson, Alfa de Cronbach e Análise de Componentes Principais; neste caso, adotou-se uma rotação varimax. O programa LISREL 8.12 permitiu informação adicional para comprovar a validade de construto do Inventário de Sexismo Ambivalente, quando foi realizada uma análise fatorial confirmatória. Neste caso, a matriz de entrada foi a de correlações, tendo sido adotado o estimador ML (Máxima Verossimilhança). Esta análise apresenta diversos indicadores de bondade de ajuste, sendo os três seguintes geralmente mencionados na literatura (Jöreskog \& Sörbom, 1989; Van de Vijver \& Leung, 1997):

- GFI (Goodness of Fit Index): compreende uma medida da variabilidade explicada pelo modelo; oscila entre .00 e 1.00 , sendo este último valor indicação de um modelo perfeito. Não é preciso na literatura um valor crítico. Por exemplo, Van de Vijver e Leung (1997) sugerem 90 como mínimo para aceitar o ajuste do modelo; e Rhee, Uleman e Lee (1990) consideram como mínimo o valor .80 . Seu ajustamento aos graus de liberdade do modelo com respeito ao número de variáveis consideradas é denominado $\underline{\mathrm{AGFI}}$, valendo o mesmo comentário quanto ao seu valor crítico ideal.

- Razão $\chi^{2 / G r a u s ~ d e ~ L i b e r d a d e: ~ e ́ ~ c o n s i d e r a d a ~}$ uma medida subjetiva da bondade de ajuste. Sugere-se que seu valor necessita ser ao menos inferior a 5.00 para indicar que o modelo é adequado (Byrne, 1989; Gouveia, 1998).

- RMSR (Root Mean Square Residual): corresponde à raiz quadrada média residual. Um valor perto de zero significa que o modelo se ajusta aos dados, indicando que todos os residuais se apresentam mais perto deste valor. Também não está muito claro que valor crítico deva assumir para que se considere o modelo adequado; Van de Vijver e Leung (1997) sugerem .05.

\section{RESULTADOS}

O objetivo principal deste estudo - lembrando foi adaptar o Inventário de Sexismo Ambivalente para uma amostra brasileira, comprovando sua validade de 
construto. Deste modo, procedeu-se inicialmente à realização de uma análise de componentes principais. $\mathrm{O}$ uso desta técnica se mostrou meritória $(\underline{\mathrm{KMO}}=, 73$; Teste de Esfericidade de Bartlett, $\chi^{2}=872,71, \mathrm{p}<$ .001) (Bisquerra, 1989). Esta solução fatorial permitiu identificar dois componentes com eigenvalue superior a 1,00, explicando conjuntamente $29,2 \%$ da variância total. Os principais resultados desta análise são apresentados na Tabela 1 .

Tabela 1. Análise de Componentes Principais do Inventário de Sexismo Ambivalente.

\begin{tabular}{llll}
\hline \multicolumn{3}{c}{ Componentes do sexismo ambivalente } \\
\hline Sexismo Benévolo (Alpha de Cronbach = .77) & $\mathbf{a}_{\text {i.f }}$ & $\mathbf{h}^{\mathbf{2}}$ \\
12 & Todo homem deve ter uma mulher a quem amar & .68 & .46 \\
13 & Homem está incompleto sem mulher & .67 & .45 \\
09 & Mulheres devem ser queridas e protegidas por homens & .60 & .36 \\
06 & Ninguém é feliz sem ter um(a) companheiro(a) & .57 & .35 \\
22 & Mulheres são mais refinadas e têm melhor bom gosto & .57 & .34 \\
17 & Uma boa mulher deve ser posta no pedestal por seu homem & .54 & .33 \\
01 & Homem não se sente completo sem o amor de uma mulher & .52 & .28 \\
08 & Mulheres têm pureza que poucos homens possuem & .51 & .25 \\
19 & Mulheres têm maior sensibilidade moral & .48 & .22 \\
20 & Homens devem prover segurança econômica a mulheres & .46 & .24 \\
03 & Em catástrofes, mulheres devem ser resgatadas primeiro & .39 & .17 \\
\hline
\end{tabular}

\section{Sexismo Hostil (Alpha de Cronbach = .66)}

15 Mulher procura controlar ao homem comprometido com ela $.72 \quad .53$

11 Mulheres procuram poder controlando aos homens $\quad \begin{array}{lll}.66 & .44\end{array}$

18 Mulheres atraem sexualmente e depois rejeitam aos .62 .39 homens

14 Mulheres exageram problemas no trabalho $\quad \begin{array}{lll}.52 & .27\end{array}$

10 Mulheres não dão valor a tudo o que os homens fazem por elas $\quad \begin{array}{rl}.52 & .30\end{array}$

04 Mulheres interpretam ações inocentes como sendo sexistas $\quad .49 \quad .23$

$\begin{array}{llll}07 & \text { Feministas procuram que as mulheres tenham mais poder } & .42 & .19\end{array}$

05 Mulheres se ofendem muito facilmente $\quad .42 \quad .17$

21 Feministas fazem demandas irracionais aos homens $\quad \begin{array}{llll}39 & .15\end{array}$

16 Mulheres alegam discriminação em derrotas justas $\quad \begin{array}{llll}.36 & .13\end{array}$

$\begin{array}{llll}02 & \text { Em nome da igualdade, as mulheres procuram privilégios } & .36 & .16\end{array}$

Nota: $\mathrm{a}_{\mathrm{i} . \mathrm{f}}=$ Carga Fatorial; $\mathrm{h}^{2}=$ Cumunalidade.

Uma saturação de \pm .30 foi assumida como satisfatória para interpretar os componentes. O primeiro deles, com eigenvalue de 3,90, reuniu 11 itens, podendo ser descrito como_Sexismo benévolo (por exemplo,_muitas mulheres se caracterizam por uma pureza que poucos homens possuem; as mulheres, em comparação com os homens, mostram um sentido refinado para a cultura e o bom gosto); sua consistência interna ( $\alpha$ de Cronbach) foi de .77. O segundo componente apresentou um eigenvalue de 2,54, estando formado por 11 itens que representam diretamente o Sexismo hostil (por exemplo, as mulheres feministas estão fazendo exigências completamente sem sentido aos homens; a maioria das mulheres não aprecia completamente tudo o que os homens fazem por elas); sua consistência interna foi de .66 .
Com o fim de reunir mais provas sobre a estrutura interna do instrumento em questão, procedeu-se a uma Análise Fatorial Confirmatória. Foram fixados dois fatores, correspondendo aos teoricamente identificados, deixando livres tanto as saturações $(\lambda$, Lambdas) como a correlação entre tais fatores ( $\phi$, Phi). Os resultados são descritos a seguir na Tabela 2 .

Tabela 2. Análise Fatorial Confirmatória do Inventário de Sexismo Ambivalente.

\begin{tabular}{llcc}
\hline \multicolumn{3}{c}{ Componentes do sexismo ambivalente } \\
\hline Sexismo benévolo & Lx & IM \\
\hline 12 & Todo homem deve ter uma mulher a quem amar & $.89 *$ & .19 \\
13 & Homem está incompleto sem mulher & $.83 *$ & .51 \\
09 & Mulheres devem ser queridas e protegidas por homens & $51 *$ & 2.08 \\
06 & Ninguém é feliz sem ter um(a) companheiro(a) & $63 *$ & 1.67 \\
22 & Mulheres são mais refinadas e têm melhor bom gosto & $35^{*}$ & .01 \\
17 & Uma boa mulher deve ser posta no pedestal por seu homem & $.40^{*}$ & 10.31 \\
01 & Homem não se sente completo sem o amor de uma mulher & $.54 *$ & .02 \\
08 & Mulheres têm pureza que poucos homens possuem & $.33 *$ & 1.59 \\
19 & Mulheres têm maior sensibilidade moral & $.38^{*}$ & 1.16 \\
20 & Homens devem prover segurança econômica a mulheres & $.30^{*}$ & 1.20 \\
03 & Em catástrofes, mulheres devem ser resgatadas primeiro & $.20 *$ & .01
\end{tabular}

\section{Sexismo Hostil}

15 Mulher procura controlar ao homem comprometido com ela $\quad 70^{*} \quad 3.63$

11 Mulheres procuram poder controlando aos homens $\quad .63^{*} \quad .07$

18 Mulheres atraem sexualmente e depois rejeitam aos homens $56^{*} \quad .51$

14 Mulheres exageram problemas no trabalho $\quad .66^{*} \quad .22$

10 Mulheres não dão valor a tudo o que os homens fazem por elas $\quad .49 * \quad 5.66$

04 Mulheres interpretam ações inocentes como sendo sexistas $\quad .37 * 2.91$

07 Feministas procuram que as mulheres tenham mais poder $\quad .39 * \quad .25$

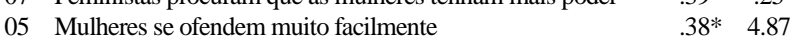

21 Feministas fazem demandas irracionais aos homens $\quad .36^{*} \quad .81$

16 Mulheres alegam discriminação em derrotas justas $\quad .47^{*} \quad 2.17$

02 Em nome da igualdade, as mulheres procuram privilégios $\quad .21 * \quad 7.80$

Nota: $\quad *$ Diferente de zero $(\mathrm{t} \geq 1.96, \mathrm{p}<.05) ; \underline{\mathrm{Lx}}=$ Lambda, Carga Fatorial; $\underline{\mathrm{IM}}=$ Índice de Modificação.

O modelo bifatorial especificado apresentou os seguintes indicadores de bondade de ajuste: $\mathbf{G F I}=.77$ e AGFI $=.72 ; \chi^{2} / \mathrm{g} .1 .=3.18$; e RMSR $=.10$; todas as saturações estimadas foram estatisticamente diferentes de zero ( $\mathrm{t}>1.96, \underline{\mathrm{p}}<.05)$. Observou-se uma ortogonalidade entre os fatores Sexismo benévolo e Sexismo hostil $(\phi=.14, \mathrm{p}>.05)$.

Com a finalidade de atender ao objetivo secundário deste estudo, conhecer o papel do gênero em relação às pontuações obtidas nos fatores de sexismo ambivalente, procedeu-se a uma correlação entre tais variáveis. $\mathrm{O}$ gênero foi tratado como uma variável dummy, assumindo os seguintes valores: $\mathbf{0}=$ Masculino, $\mathbf{1}=$ Feminino. Observou-se uma correlação significativa e direta entre esta variável e o Sexismo benévolo $(\underline{r}=.19 ; \underline{p}<.01)$, sendo inversa enquanto ao Sexismo hostil $(r=-14 ; p<.05)$. Para conhecer mais claramente a magnitude da diferença entre os gêneros em relação a estes fatores do sexismo, foi efetuada uma comparação através do teste 
t para amostras independentes; os resultados são resumidos na Tabela 3 .

Tabela 3. Dimensões do Sexismo Ambivalente entre Homens e Mulheres.

\begin{tabular}{lcccccccc}
\hline & \multicolumn{4}{c}{ Gênero } & & \multicolumn{2}{c}{} \\
\cline { 2 - 6 } & \multicolumn{2}{c}{ Homem } & \multicolumn{2}{c}{ Mulher } & \multicolumn{2}{c}{ Estatísticas } \\
\hline Sexismo Ambivalente & M & DP & M & DP & $\underline{\mathbf{t}}$ & gl & $\mathbf{~}<$ \\
\hline Benévolo & 29,7 & 6,09 & 32,8 & 5,79 & $-2,65$ & 192 & .01 \\
Hostil & 27,1 & 5,43 & 24,9 & 5,36 & 2,00 & 194 & .05 \\
\hline
\end{tabular}

Observando as médias na tabela acima é possível visualizar as diferenças entre homens e mulheres no que diz respeito ao sexismo. Especificamente, as mulheres apresentaram uma média superior $(\underline{M}=32,8$, $\underline{\mathrm{DP}}=5,79)$ à dos homens $(\underline{\mathrm{M}}=29,7, \underline{\mathrm{DP}}=6,09) \mathrm{em}$ relação ao Sexismo bénevolo $[\mathrm{t}(192)=-2,65, \mathrm{p}<$ .01]. Esta situação se inverteu no caso do Sexismo hostil, com os homens pontuando mais alto $(\underline{\mathrm{M}}=27,1$, $\underline{\mathrm{DP}}=5,43)$ do que as mulheres $(\underline{\mathrm{M}}=24,9, \underline{\mathrm{DP}}=5,36)$ $[\mathrm{t}(194)=2,00, \mathrm{p}<.05]$. Comparando-se a prevalência na amostra estudada dos dois tipos de sexismo, tratados como medidas repetidas, observa-se que o benévolo é equivalente ao hostil entre os homens [ $t$ $(28)=1,77, \underline{\mathrm{p}}>.05]$, porém é superior entre as mulheres [t $(160)=14.69, \underline{p}<.001]$.

\section{DISCUSSÃO}

Embora o tamanho $(\underline{\mathrm{N}}=200)$ e as características (estudantes universitários) da amostra considerada não permitam assegurar definitivamente a adaptação do Inventário de Sexismo Ambivalente para a população brasileira, foram reunidas provas a seu favor. Concretamente, demonstrou-se a existência de uma estrutura fatorial simples, bastante condizente com a observada em estudos anteriores (Expósito, Moya \& Glick, 1998; Glick \& Fiske, 1996; Mladinic \& cols., 1998). Os dois fatores de sexismo, benévolo e hostil, são visíveis na análise exploratória dos componentes principais, e são corroborados através da Análise Fatorial Confirmatória. Neste último caso, os indicadores de bondade de ajuste não são os ideais (Van de Vijver \& Leung, 1997), porém apóiam a presença do modelo teórico em discussão (as cargas fatoriais dos itens nos respectivos fatores são todas estatisticamente diferentes de zero). $\mathrm{O}$ índice de consistência interna do fator sexismo benévolo $(\alpha$.77) é equivalente ao encontrado no Chile ( $\alpha=.77$; Mladinic \& cols., 1998) e nos Estados Unidos ( $\alpha$ médio $=.78$; Glick \& Fiske, 1996). Não obstante, o fator sexismo hostil apresenta consistência interna no
Brasil $(\alpha=.66)$ inferior aos índices observados naqueles dois países ( $\alpha=.86$ e .88 , respectivamente). Este aspecto sugere rever a tradução semântica e cultural dos itens que compõem este fator, inclusive não descartando a possibilidade de elaborar novos itens que venham a expressar mais adequadamente seu conteúdo subjacente.

Tudo leva a pensar que existe uma forma mais ancestral de sexismo, o hostil, que na atualidade comparte cenário com uma forma sutil, identificada como sexismo benévolo. No presente estudo estes não representam dimensões plenamente interdependentes (Glick \& Fiske, 1996) ou elas são contrárias (Mladinic \& cols., 1998); mais bem compreendem estruturas ortogonais, sendo possível que cada indivíduo apresente tanto um como outro tipo destas orientações na mesma magnitude.

Finalmente, em termos das diferenças de sexismo entre os gêneros, os resultados encontrados aqui são diferentes daqueles observados no Chile (Mladinic \& cols., 1998), onde os homens foram fundamentalmente sexistas ambivalentes $(63,3 \%)$, enquanto as mulheres se distribuíram de modo equivalente entre sexistas ambivalentes (40\%) e hostis $(38,2 \%)$. Na presente amostra se comprovou estatisticamente uma maior média de sexismo hostil entre os homens e de benévolo entre as mulheres. Talvez o padrão cultural existente em cada país ajude a explicar estes resultados. Os brasileiros apresentam uma orientação mais hierárquica e instrumentalista que os chilenos, os quais dão mais importância a trabalhos onde possam cooperar uns com os outros e ter boas relações de trabalhos com seus superiores diretos (Hofstede, 1991). Por certo, este aspecto do tipo de orientação cultural e a direção do sexismo assumido pelas pessoas deveriam merecer atenção no futuro.

\section{CONCLUSÃO}

Espera-se que os objetivos deste estudo tenham sido cumpridos. Foram apresentadas provas sobre a adequação do Inventário de Sexismo Ambivalente (Glick \& Fiske, 1998), especificamente sobre sua validade de construto e relação com o gênero. Observou-se que o sexismo ambivalente compreende uma estrutura bidimensional, expressando um conjunto de estereótipos quanto à avaliação cognitiva, afetiva e atitudinal sobre o papel apropriado que cada indivíduo deve ocupar ou executar na sociedade, segundo o seu gênero (Expósito, Moya \& Glick, 1996). 
Reconhece-se aqui que as valorizações atribuídas ao homem e à mulher se mostram diferentes, e a razão pode estar em múltiplos indicadores (por exemplo, sociais, econômicos, etc.), não se limitando a diferenças biologicamente instituídas (Moya, 1990). Como resultado também desta concepção, começaram a se configurar as formas de sexismo ambivalente antes tratadas. Seu impulso no meio acadêmico, certamente, se deveu às pesquisas realizadas sobre a existência de um "novo racismo" (Pettigrew \& Meertens, 1995), destacand-se que as expressões discriminativas adquirem uma nova concepção e manifestação sutil também entre os sexos (D'Amorim, 1997).

A aparição do sexismo benévolo é sem dúvida um problema no âmbito da pretendida relação de igualdade e de justiça social. Diferente do sexismo hostil, cuja manifestação é evidente e, portanto, permite ser diretamente atacada, esta forma mais sutil escapa mesmo aos olhos dos mais críticos. Mascara-se a discriminação contra a mulher ao tratá-la como um ser especial, frágil e que necessita de cuidados. Neste sentido, talvez a discrininação diminua o rechaço da sua participação no mercado de trabalho, mas não liberta a mulher do poder e da dominação do homem. Isto, obviamente, poderá refletir as condições econômicas assimétricas entre ambos os gêneros já ressaltadas anteriormente. Neste cenário, longe de estabelecer um clima de insegurança e isolamento entre estes atores socais, um elogio ou uma gratidão muitas vezes não passam de ser a outra cara da moeda há muito conhecida: o sexismo. O instrumento de medida aqui considerado não permitirá mudar esta situação, mas ao menos dará condições para conhecer sua extensão e antecipar suas consequiências; isto o faz útil nos estudos que tratem da questão do preconceito contra as mulheres.

Para finalizar, Fraisse (1991) considera que a diferença sexual entre homens e mulheres no decorrer da última década vem sendo mais saliente principalmente em relação aos valores que os regem. Estudos que contemplem este conteúdo deveriam ser esperados no futuro; a pesquisa de D’Amorim (1997) representa uma contribuição no âmbito atitudinal. No entanto, por sua natureza mais duradoura e universal (Rokeach, 1993), os valores humanos deveriam merecer uma atenção especial, comprovando-se a possibilidade de modificá-los para intervir diretamente nas próprias atitudes e nos comportamentos sexistas. É importante conhecer, por exemplo, que valores fomenta cada um dos tipos de sexismo aqui tratados.

\section{REFERÊNCIAS BIBLIOGRÁFICAS}

Allport, G. W. (1954). The nature prejudice. Reading, MA: AdisonWesley Publishing Company.

Archier, J. (1996). Sex differences. Em A. S. R. Manstead \& M. Hewstone (Eds.), The blackwell encyclopedia of social psychology (pp. 520-524). Oxford: Blackwell Publishers.

Bisquerra, A. R. (1989). Introducción conceptual al analísis multivariable: Un enfoque informático con los paquetes SPSS$X, B M P D$, LISREL y SPAD. Barcelona: PPU.

Borelli, A. (1998). Gênero: Desafios e perspectiva. Revista Unicsul, 4, 79-84.

Byrne, B. M. (1989). A primer of LISREL: Basic applications and programming for confirmatory factor analytic models. New York: Springer-Verlag.

D’Amorim, M.A. (1997). Estereótipos de gênero e atitudes acerca da sexualidade em estudos sobre jovens brasileiros. Temas em Psicologia, 3, 121-134.

De Tocqueville, A. (1835 / 1993). La democracia en América. Madrid: Alianza Editorial.

Eagleton, T. (1998). As ilusões do pós-modernismo. Rio de Janeiro: Jorge Zahar Editor.

Expósito, F., Moya, M. C., \& Glick, P. (1998). Sexismo ambivalente: Medición y correlatos. Revista de Psicologia Social, 13, 159-169.

Ferreira, M. C. (1995a). Masculinidade, feminilidade e ajustamento. Psicologia: Reflexão e Crítica, 8, 205-224.

Ferreira, M. C. (1995b). Questionário Estendido de Atributos Pessoais: Uma medida de traços masculinos e femininos. Psicologia: Teoria de Pesquisa, 11, 2, 155-161.

Fraisse, G. (1991). Da destinação ao destino. História filosófica da diferença entre os sexos. Em G. Duby \& M. Perrot (Org.), História das mulheres no Ocidente. Século XIX. pp. 59-96. Porto, Portugal: Afrontamento.

Fukuyama, F. (2000). A grande ruptura: A natureza humana e a reconstituição da ordem social. Rio de Janeiro: Rocco.

Fundação Carlos Chagas (1998). Banco de dados sobre o trabalho das mulheres. Home Page: http://www.fcc.org.br/pesquisa/rgenero/bdtrabfm/ (consultada em 31.08.2000).

Glick, P., \& Fiske, S. T. (1998). The Ambivalent Sexism Inventoy: Differentiating hostile and benevolent sexism. Journal of Personality and Social Psychology, 70, 491-521.

Goldwert, M. (1985). Mexican machism: The flight from femininity. Psychoanalytic Review, 72, 161-169.

Gouveia, V.V. (1998). La naturaleza de los valores descriptores del individualismo y del colectivismo: Una comparación intra e intercultural. Tese de Doutorado, Faculdade de Psicologia, Universidade Complutense de Madri, Espanha.

Hofstede, G. (1991). Cultures and organizations: Software of the mind. London: McGraw-Hill.

Hutz, C. S. \& Koller, S. H. (1992). A mensuração de gênero: Uma readaptação do BSRI. Psicologia: Reflexão e Crítica, 5, 2, 15-21.

Jöreskog, K.G. \& Sörbom, D. (1989). LISREL 7 user's reference guide. Mooresville, IN: Scientific Software. 
Katsurada, E., \& Sugihara, Y. (1999). A preliminary validation of the Bem Sex Inventory in Japanese culture. Journal of CrossCultural Psychology, 30, 641-645.

Lenney, E. (1991). Sex roles: The measurement of masculinity, femininity, and androgyny. Em J. P. Robison, P. R. Shaver, \& L. S. Wrightsman (Org.), Measures of Personality and Social Psychological Attitudes. Measures of social psychological attitudes, vol. 1 (pp. 573-660). San Diego, CA: Academic Press.

Mladinic, A., Saiz, J. L., Díaz, M., Ortega, A., \& Oyarce, P. (1998). Sexismo Ambivalente en estudiantes universitarios chilenos: Teoría, medición y diferencias del género. Revista de Psicología Social y Personalidad, 14, 1-14.

Moraes, A. (1998). Direito constitucional, $3^{\text {a }}$ edição. São Paulo: Editora Atlas.

Moya, M. C. (1990). Favoritismo endogrupal y discriminación exogrupal en las percepciones de las características sexoestereotipadas. Em G. Musitu (Org.), Procesos psicosociales básicos (pp. 221-228). Barcelona: PPU.

Outram, D. (1997). La langage mâle de la vertu: As mulheres e o discurso da Revolução Francesa. Em P. Burke \& R. Porter (Org.), História social da linguagem (pp. 141-160). São Paulo: Editora Unesp / Cambridge University Press.

Páez, D., Torres, B., \& Echebarria, A. (1990). Esquema de si, representación social y estereotipo sexual. Em G. Musitu (Org.), Procesos psicosociales básicos (pp. 229-234). Barcelona: PPU.

Pena, M. (1991). Class, gender, and machismo: The treacherouswoman folklore of Mexican male workers. Gender \& Society, 5, 30-46.

Pettigrew, T.F., \& Meertens, R.W. (1995). Subtle and blantant prejudice in western Europe. European Journal of Social Psychology, 25, 57-75.

Pringle, R. (1997). Feminist theory and the world of the social. Current Sociology, 45, 75-89.

Radice, J. (1987). Papéis sexuais no Nordeste do Brasil: Sua desejabilidade e possíveis consequiências para a auto-realização da mulher. Revista de Psicologia, 5, 93-103.

Rhee, E., Uleman, J.S., \& Lee, H.K. (1996). Variations in collectivism and individualism by ingroup and culture:
Confirmatory factor analysis. Journal of Personality and Social Psychology, 71, 1037-1054.

Rokeach, M. (1973). The nature of human values. New York: Free Press.

Siano, J. A. (2000). Constituição da Republica Federativa do Brasil. São Paulo: Editora Rideel.

Souza, M. A., \& Ferreira, M.A.C. (1997). Identidade de gênero masculina em civis e militares. Psicologia: Reflexão e Crítica, $10,301-314$

Spence, J. T., Helmreich, R., \& Stapp, J. (1975). Ratings of self and peers on sex role attributes and their relation to self-esteem and conceptions of masculinity and feminility. Journal of Personality and Social Psychology, 32, 29-39.

Steinmann, A. (1977). Vingt ans de recherches sur les rôles des sexes. Em A. Michel (Org.), Femmes, sexisme et sociétés (pp. 101-116). Paris: Presses Universitaires de France.

Swin, J. K., Aikin, K. J., Hall, W. S., \& Hunter, B. A. (1995). Sexism and racism: Old-fashioned and modern prejudices. Journal of Personality and Social Psychology, 68, 199-214.

Torres, J. B. (1998). Masculinity and gender roles among Puerto Rican men: Machismo on the US Mainland. American Journal of Orthopsychiatry, 68, 16-26.

Unger, R. K. (1979). Toward a redefinition of sex and gender. American Psychologist, 34, 1085-1094.

Van de Vijver, F., \& Leung, K. (1997). Methods and data analysis for cross-cultural research. Thousand Oaks, CA: Sage Publications.
Recebido em 11/01/2002

Revisado em 02/05/2002

Aceito em 10/05/2002 